\title{
NOTA SOBRE A "SÁTIRA GERAL A TODO O REINO, E GOVERNO DE PORTUGAL"
}

\author{
João Adolfo Hansen, Marcello Moreira e Caio Cesar Esteves de Souza
}

O autor anônimo da "Sátira geral a todo o Reino, e governo de Portugal" recorreu ao famigerado nome daquele homem que, segundo Manuel Pereira Rabelo, em Vida do excelente poeta lírico, o doutor Gregório de Matos e Guerra, morreu em 1696 em Recife, onde vivera os derradeiros anos de uma vida desvairada. Ressuscitado na mesma cidade em 6 de agosto de 1713, compôs quarenta décimas de dez redondilhos maiores ou versos de sete sílabas, ordenados em grupos de quatro, três e três. Em geral, os quatro primeiros funcionam como apresentação de um tema e considerações sobre ele; os três ou quatro seguintes o amplificam; os três últimos, às vezes os dois últimos, concluem. Por exemplo, a estrofe 1:

\footnotetext{
Apresentação

Um reino de tal Valor

e de povo tão honrado

é justo seja louvado

desde o vassalo ao Senhor.
}

\section{Desenvolvimento}

Inda que fraco orador

a verdade hei de dizer,

e cada qual recolher

pode, aquilo que lhe toca

\section{Conclusão}

Inda que diga, o provoca

uma imitação real

Este é o bom governo de Portugal. 
A matéria das quarenta estrofes são os vícios fortes, ou nocivos, do "bom governo de Portugal”. Cômicos, não causam riso, mas horror, merecendo a vituperação maledicente da persona poética Gregório de Matos ressuscitado; a matéria "bom governo de Portugal” é figurada em estilo baixo. A persona inicia a vituperação pela cabeça do corpo político do Reino, o Rei. No caso, um menino sem discernimento que, contente com a adulação, tem e permite vícios que corrompem o bem comum. Afirmando que o governo tiraniza a pobreza e que tipos inferiores invertem a ordem natural das coisas, o poema põe em cena o ordenamento jurídico do pacto de sujeição pelo qual a comunidade, como uma única vontade unificada do corpo político definido como "corpo místico", abre mão de sua liberdade e, declarando-se súdita ou subordinada a um só, recebe a representação dos estamentos e ordens sociais que a hierarquizam com seus privilégios e deveres. O rei constituído no pacto de sujeição deve governar por meio de leis positivas que, para serem não só legais, mas antes de tudo legítimas, devem refletir a justeza e a justiça da lei natural da Graça, que reflete a lei eterna de Deus. Como o poema afirma, as ações das autoridades de todas as instâncias do governo de Portugal são ilegítimas, por isso contrariam a lei natural; ao fazê-lo, negam a lei eterna de Deus. Logo, a sátira é feita para denunciar o pecado que, dissolvendo a sacralidade do pacto de sujeição, corrompe as instituições e homens que deveriam zelar pela boa ordem social. Veja-se, estrofe a estrofe, a somatória dos vícios: o pecado corrompe o Conselho de Estado e seu secretário, Dioguinho de Mendonça (estrofe 6); o Conselho de Guerra e os cargos dados aos mochilas, criadinhos pajens (9); a Junta dos Três Estados e seu tesoureiro "lagarto fatal", crocodilo devorador de tributos (10); a Contadoria, que sempre nega informação, enquanto rapina (11); o Conselho da Fazenda, onde os pobres esperam anos a fio, sempre fraudados (12); o Desembargo do Paço, onde juízes togados com peles de chinchila são canalha presidida por um Duque (13); o Conselho Ultramarino, presidido por diabo corruptor (14); o Governador, fraco, traidor e corrupto (15); a Mesa de Consciência, que consciência não tem (16); a Relação, cujo bispo regedor é mau ladrão (17); os Armazéns e Consulado, regidos por razões de bêbados (18); a Junta do Comércio, que um Marialva depena, dando dinheiro sem conta para as casas de um pecador, o Serra (19); a Alfândega onde o Provedor tudo gasta que vem do Brasil (20); o estanco do tabaco presidido por um Minas que se enche de propinas (21); a Casa da Índia e Contos com vedorias, tesouros e chancelarias roubados (22); o Senado da Câmara que monturos permite e espalha (23); os Ministros da Justiça, que nunca a fazem, ou pela puta, ou por cobiça (24); os Ministros da Igreja, fradalhada e clerezia, e sua simonia (25); os Assentistas, que tomam o trigo aos lavradores (28); as Conquistas, 
governadas por sujeitos ridículos sem obras, ações ou feitos (29); a fidalguia corrupta (30); as donzelas que selam o vaso com terebentina para voltarem à posse de um hímen virginal (31); as casadas de honras manchadas e as viúvas sem juízo e renda pretendendo segundo himeneu (32 e 33); os estrangeiros que levam o ouro e a prata sem conselheiro que os impeça (34); os maraus que roubam na rua e, tendo a amizade de Conde e Marquês, são livres (35); os atravessadores de trigo, azeite, vinho, ladrões do povo (36); a canalha vil dos mercadores vendilhões (35). E:

\author{
Já que não temos que esperar \\ neste governo insolente, \\ mais, que padecer a gente, \\ sem o bem nunca alcançar, \\ só para Deus apelar \\ pode o Povo português \\ e pedir-lhe desta vez \\ que nos dê governo novo (39)
}

O que talvez ocorra, conclui o poema, quem sabe quando El Rei D. Sebastião ressuscitar e voltar (40).

A versão do poema ora publicada encontra-se no ms. $68, \mathrm{n}^{\circ}$ 53, depositado na Biblioteca Nacional de Lisboa. Ela foi encontrada por Caio Cesar Esteves de Souza. Quando da edição, manteve-se a pontuação do manuscrito e empreendeu-se a normalização ortográfica do texto. Um único verso não pôde ser transcrito, pois parte do papel em que estava inscrito foi perdida; as perdas estão marcadas com $\left(^{*}\right)$. 
Sátira geral a todo o Reino, e governo de Portugal; por Gregório de Mattos ressuscitado em Pernambuco, no ano de 1713 a 6 de agosto do dito ano e feita com este Mote:

Este é o bom Governo de Portugal

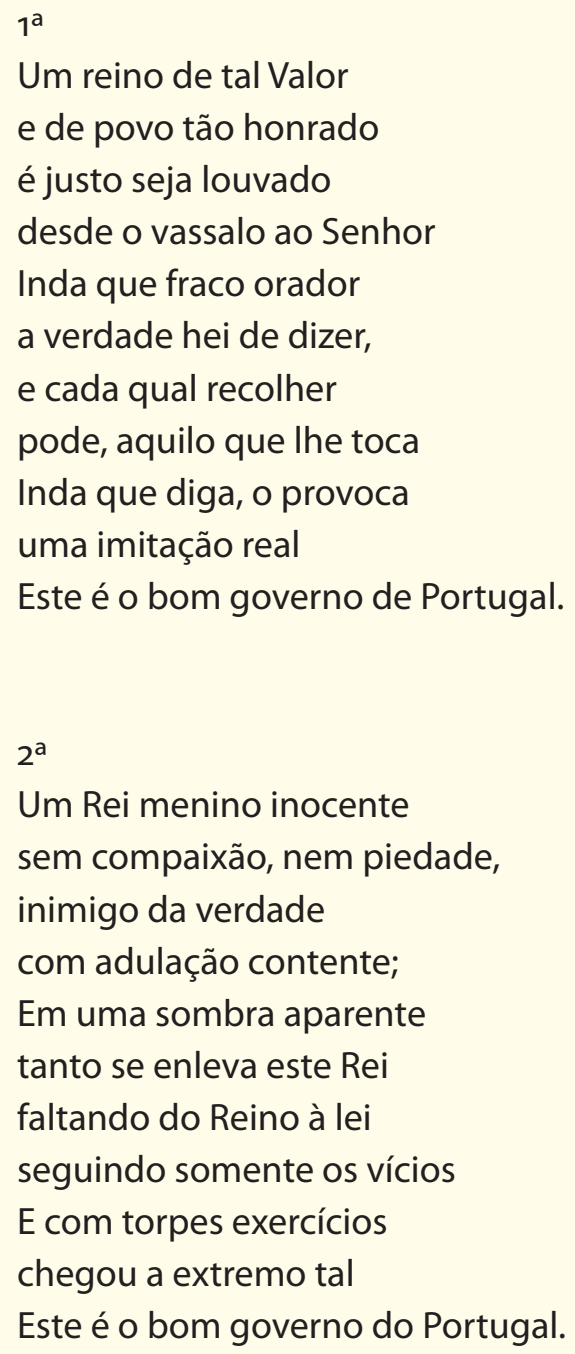


$3^{\mathrm{a}}$

Pera os Povos bem reger,

Deus o pôs neste lugar

não para os desgovernar

nem para o Reino perder:

Mas creio lhe fazem crer

que é já virtude o pecar

e o que deve não: pagar

ter ambição, e avareza

Tiranizar a Pobreza

com tributo desigual

Este é o bom governo de Portugal.

$4^{\mathrm{a}}$

Pois um Infante inumano

e insolente matador

que sem ter de Deus temor

vive bruto; e corre insano:

É o mais cruel tirano

que neste reino se há visto

e que conhecendo isto

o tolinho do Irmão

Ihe não deu uma prisão

para evitar tanto mal

Este é o bom governo de Portugal. 
$5^{\mathrm{a}}$

Um neto de um Correeiro

hoje Príncipe da Igreja

que alcança quanto deseja,

adulando lisonjeiro:

Sambixuga do dinheiro

que se rouba da pobreza

porque chega a tal grandeza

quem ontem morrendo à fome

Sem ser visto, nem ter nome

hoje esteja cardeal

Este é o bom governo de Portugal.

$6^{\mathrm{a}}$

Que haja um Conselho de Estado

para mil resoluções

e que em todas as ações

é sempre desacertado:

Se é de seus desacertos

por segredos descobertos

que só por os bons intentos

Ihe cega os entendimentos

o grão ministro infernal

Este é o bom governo de Portugal. 
$7^{\mathrm{a}}$

Também o seu Secretário

Dioguinho de Mendonça

ar dando por gerigonça

no espaço imaginário:

Sempre aberto o calendário

tem de mentiras e enganos

que com cara de cem anos

vivam assolando o mundo

Eu juro, que me confundo

vendo o que um magano val

Este é o bom governo de Portugal.

$8^{\mathrm{a}}$

Um Messias das Mercês

feito mosca atordoada,

que El-Rei não despacha nada

diz a todo o Português;

Todos conhecem que fez

em breve tempo Palácio

porque estudou mais de espácio

na sua conveniência

sendo piadosa aparência

para exercício usual

Este é o bom governo de Portugal. 
$9^{\mathrm{a}}$

Que no Conselho de Guerra

os pobres dos pertendentes

andem feitos pacientes

rapando com os pés a terra:

E vendo que se desterra

daqui o merecimento

pelo injusto provimento

dos postos, que estes Salvagens

Dão a mochilas e a pagens

dizem deste Tribunal

Este é o bom governo de Portugal.

$10^{\mathrm{a}}$

A Junta dos três Estados

que as rendas reais despende

onde todo o que pertende,

vai purgar os seus pecados:

Despois que tem bem surrados

os ossos, na pertensão

com uma e outra informação

o mandam ao tesoureiro

O qual diz não tem dinheiro

por ser lagarto fatal

Este é o bom governo de Portugal. 
$11^{\mathrm{a}}$

A nossa Contadoria

onde o máximo é registo

porque na junta o que é visto

se remete a esta via:

Se falta aqui a valia

para a boa informação

acha-se uma dilação

e uma dívida no cabo

Que até o mesmo diabo

dirá por regra geral

Este é o bom governo de Portugal.

$12^{\mathrm{a}}$

O Conselho da Fazenda

com dúvidas, e demoras

passam anos, dias, e horas

os pobres, nesta contenda

Em dilação estupenda

três anos aqui andei

e na verdade não sei

como o posso referir,

Não houve que deferir

foi o despacho final

Este é o bom governo de Portugal. 
$13^{\mathrm{a}}$

Um Desembargo do Paço

composto de vós, chinchilhas,

que com roupões, e golilhas

governam o reino de espaço

Os corações têm de aço

estes soberbos vilões

pois de seus maus corações

o mal a todo se espalha

E presida a tal canalha

um Duque de Cadaval

Este é o bom governo de Portugal.

$14^{\mathrm{a}}$

O Conselho de Ultramar

onde preside um diabo

que assim Ihe vai dando cabo

vendendo o que se há de dar

E espera de se salvar

este assolador da gente

tão soberbo, e insolente

que ao Rio de Janeiro

Todos dizem por dinheiro

vendera este irracional

Este é o bom governo de Portugal. 
$15^{\mathrm{a}}$

E que haja o Reino de ter

a um Rei, tão desumano

que deixou passar um ano

sem o mandar se correr

E que ainda favorecer

queiram ao Governador

que por fraco, e por traidor

dando gosto a S. Vicente

Desacreditasse a gente

com uma perda universal

Este é o bom governo de Portugal.

$16^{\mathrm{a}}$

A Mesa da Consciência

que consciência não tem

onde a todo o que ali vem

faz perder a paciência

Com uma, e outra, diligência

em qualquer Inquirição

traz arrastado um cristão

que quer por a cruz de Cristo

E se as cruzes não tem visto

não se acha a voz paternal

Este é o bom governo de Portugal. 
$17^{\mathrm{a}}$

Cheguemos à Relação

onde um bispo regedor

deixa de ser bom Pastor

para ser um mau ladrão

Despois que empunha o bastão

com presunções de letrado

tem muita gente enforcado

e atropelando aos povos

Ihe quer dar costumes novos

por seu destino brutal,

Este é o bom governo de Portugal.

$18^{a}$

Armazéns e Consulado

que está regendo a fronteira

com rezões de borracheira

descompondo a todo o honrado

Porque foi tão bom soldado

no choque de Badajoz

nesta ocupação o pôs

por seus serviços El-Rei

E se decreto, ordem, ou lei

arrepugna este animal

Este é o bom governo de Portugal. 
$19^{\mathrm{a}}$

A Junta que não tem pelo

do Comércio porque calva

a deixou o Marialva

custou a vida ao Rabelo

Porque dizem nesta terra

que para as casas do Serra

dera dinheiro sem conto

porque o queria ter pronto

para o pecado carnal

Este é o bom governo de Portugal.

$20^{\mathrm{a}}$

Pois da Alfândega a descarga

onde o Porvedor gentil

todo o que vem do Brasil

quer despender, com mão larga

$E$ se o não faz, lhe é amarga

a descarga do Navio

e os anos atrás, no Rio,

carregados, se perderam

Que como não concorreram

Concorreu-lhe o temporal

Este é o bom governo de Portugal. 
$21^{a}$

O estanco do Tabaco

aonde preside o Minas

de ordenados, e propinas

mui bem se enche o velhaco

la-lhe chegando ao lado

com um bastão estrangeiro

e o filho bom cavaleiro

deteve a cavalaria;

Quando o inimigo fugia

de coura no azinhal

Este é o bom governo de Portugal.

$22^{a}$

A Casa da Índia, e Contos

com todas as vedorias

tesouros, chancelarias,

mui bem lhe vejo os pespontos,

Ainda que sutis seus pontos

eu Ihos conheço de sorte,

que se governara a corte,

eu Ihe vazara as enchentes,

Pois destas vias correntes

Só eu lhe sei o canal

Este é o bom governo de Portugal. 
$23^{\mathrm{a}}$

Da Câmara, e Senado

que em obras, tachas, limpeza

deve com toda a presteza

ter particular cuidado

O governo, é desastrado

sob as ruas da cidade

monturos, e porquidade,

e o que tem que vender

o vende pelo que quer

por ter seguro o costal

Este é o bom governo de Portugal.

$24^{\mathrm{a}}$

Os Ministros de Justiça

que nunca a fazem direita

porque a valia respeita

pela Puta ou por cobiça

O Demo, assim Ihe atiça

este fogo, em seus ardores

Juízes, Corregedores,

Letrados, e Escrivães,

Alcaides, Tabaliães,

todos vestem de um saial

Este é o bom governo de Portugal.

Teresa revista de Literatura Brasileira [17]; São Paulo, 2016 • 181 
$25^{a}$

Pois os Ministros da Igreja

fradalhada, e clerezia,

em todos há simonia,

tudo ambição tudo inveja,

Não há nenhum que não seja

um preverso amancebado

outro para ser prelado

a Roma manda o dinheiro

Para que pronto, e ligeiro,

Ihe venha um moto papal

Este é o bom governo de Portugal.

$26^{a}$

Que queira El-Rei sustentar

nas praças e na campanha

a gente, com traça e manha,

e sem lhe querer pagar?

$E$ andam isto aturar

os miseráveis soldados

famintos, e trabalhados

Ludíbrios padecendo

Sempre de fome morrendo

sem Ihe darem um só real

Este é o bom governo de Portugal. 
$27^{\mathrm{a}}$

E pois à guerra mandar

com palavras, e enganos

com quatro pobres maganos

e sem lhe dar de comer?

Bem pudera conhecer

pois Ihe dá tão pouco disto

nos sucessos que tem visto

depois que o cetro empunhou

Que vitória não alcançou

pois Ihe tem ódio mortal

Este é o bom governo de Portugal.

$28^{\mathrm{a}}$

Os Assentistas sem lei

do Reino destruidores

que o trigo, aos lavradores

tomam, com o poder de El-Rei:

Não lhe pagando, eu o sei,

para o tornarem a vender

deixando à fome morrer

del-Rei a cavalaria,

E a Pobre Infantaria

e sofra isto um general?

Este é o bom governo de Portugal. 
$29^{a}$

Que às conquistas governar

mandem, para desabonos,

uns pataratas, fanchonos

sem para nada prestar:

E que se andem aumentar

uns ridículos sujeitos

sem obras, ações, nem feitos,

e se há tal ocasião

De ter copada na mão

a fuga Ihe é cordial

Este é o bom governo de Portugal.

$30^{a}$

Que a mais da fidalguia

que na soberba se enfronha

neles se acha sem vergonha

toda a má velhacaria:

A fraqueza, e covardia,

levam contra os castelhanos;

e para os pobres paisanos

são uns tigres, e uns leões,

Mas porão nos seus brasões

um proceder tão cabal

Este é o bom governo de Portugal. 
$31^{\mathrm{a}}$

O que direis das donzelas

com escrúpulos dobrados

e tendo os pontos quebrados

vos colhem nas esparrelas

Despois de várias barrelas

e ter três vezes parido

enganam o pobre Marido,

e um virgo de tromentina

Encaixando-se à menina

em possessão virginal

Este é o bom governo de Portugal.

$32^{\mathrm{a}}$

Também se veem as casadas

que por quererem brilhar

prazer, joias, galear,

e serem mui regaladas,

As honras trazem manchadas

porque o pobre do Marido

como não dá o vestido

nem para a casa o sustento

À mulher consentimento

dá com que governe o casal

Este é o bom governo de Portugal.

Teresa revista de Literatura Brasileira [17]; São Paulo, 2016 • 185 
$33^{\mathrm{a}}$

Que a pobre desconsolada

da viúva sem marido

o capelo traga erguido,

e a cabeça apolvilhada;

Mui cheirosa, e perfumada

segundo himeneu pertenda

sem ter juízo, nem ter renda,

sempre a presunção é alta

E se acaso um Noivo falta

não Ihe falta um provincial

Este é o bom governo de Portugal.

$34^{\mathrm{a}}$

Venha todo o Estrangeiro

e cada um negociando

o ouro, e prata vão levando

deixando-nos sem dinheiro,

E não haja conselheiro

que seja homem de talento

que apurando o entendimento

algum remédio lhe aplique.

Para que o reino, não fique

exausto, deste metal

Este é o bom governo de Portugal. 
$35^{\mathrm{a}}$

Que andem por esta cidade

roubando, vários maraus,

e que estes vaganaus

tenham favor, e amizades

Sem ter honra, nem verdades

furtando uma, e outra vez

achando o Conde, e o Marquês

que dizem, se presos vão,

São da sua obrigação,

ao Ministro Principal

Este é o bom governo de Portugal.

$36^{\mathrm{a}}$

Pois uns atravessadores

de trigo, azeite, e de vinho,

que são por todo o caminho

do povo, uns assoladores

Porque da fome os rigores

todos fazem padecer

e que haja de se sofrer

que qualquer bisbilhoteiro

Incorra, por ter dinheiro

em caso tão criminal

Este é o bom governo de Portugal. 
$37^{\mathrm{a}}$

Toda a mais canalha vil, mercadores, vendilhões,

que estão ganhando milhões

com emprego de um ceitil

Tem toda a traça gentil

para poderem roubar

podendo isto emendar

com açoutes e galés

Porque assim, em que lhe pês

tenham menos cabedal

Este é o bom governo de Portugal.

$38^{\mathrm{a}}$

O mais que aqui não refiro

fique à eleição dos leitores

que de tão graves horrores

muito pouco já me admiro

Corre a fortuna seu giro

com mil voltas, e rodeios

pois que por tão vários meios

vivem neste reino insano

O bom, o mau, alto, e magano,

e como quer cada qual

Este é o bom governo de Portugal. 
$39^{\mathrm{a}}$

Já não temos que esperar neste governo insolente;

mais, que padecer a gente,

sem o bem nunca alcançar:

Só para Deus apelar pode o Povo português

e pedir-lhe desta vez que nos dê governo novo, Para que com ele o Povo, diga, no seu natural Este é o bom governo de Portugal.

$40^{a}$

Quando aquele Santo Rei que em alcácer foi vencido pelejando inadvertido contra o poder de Muley A exaltar de Cristo a Lei sair pode divino acerto de donde está encoberto com verdade, e com rezão,

Dirá a nossa nação tendo um cetro imperial Este é o bom governo de Portugal. 


\section{Glossário}

Alcácer s.m. - antiga fortaleza ou castelo fortificado.

Assentista s.m. - beneficiário de bens, atos ou fatos jurídicos, ou de atividades econômicas e profissionais que são objeto de tributação.

Azinhal s.m. - conjunto de azinheiros.

Barrela s.f. - água em que se ferveu cinza, usada para branquear roupa.

Ceitil s.m. - moeda portuguesa antiga, com o valor de um sexto de real.

Chinchilha s.f. - o mesmo que chinchila; designa homens excessivamente recobertos por roupas e peles.

Copada s.f. - copo cheio.

Cordial s.m. - medicamento ou bebida que fortalece.

Costal s.m. - as costas, ou também os flancos.

Coura s.m. - armadura de couro para proteger costas e peito; proteção, guarida; o homem que se apresenta guarnecido de coura.

De espácio adv. - sem pressa, lentamente.

Fanchono s.m. - sodomita.

Golilha s.f. - gola com a volta engomada.

Lagarto fatal s.m. - expressão com que se nomeia o crocodilo do Nilo, que come a presa enquanto fingidamente chora por ela.

Magano s.m. - indivíduo de baixa extração.

Marau s.m. - malandro, patife, pirata.

Mochila s.m. - rapaz de pequeníssima nobreza, sem idade para portar espada, e que corria à frente do carro ou cavalo de seu senhor.

Patarata s.m. - ostentação ridícula, mentira; pessoa dada a pataratas.

Pertendente s.m. - o mesmo que pretendente.

Pertensão s.f. - o mesmo que pretensão.

Porvedor s.m. - o mesmo que provedor.

Saial s.m. - antiga vestidura grosseira.

Sambixuga s.m. - o mesmo que sanguessuga, parasita.

Simonia s.f. - tráfico de coisas sagradas ou espirituais.

Traça s.f. - manha, ardil.

Tromentina s.f. - o mesmo que tormentina, ou terebentina; resina extraída de árvores, empregada para fazer mulher sexualmente ativa parecer novamente virgo.

Vaganau s.m. - que vagueia, errante; vagabundo;

Virgo s.f. - virgem. 